\title{
LIBERTAD DE EXPRESIÓN, INDEPENDENCIA, IMPARCIALIDAD: LOS JUECES EN LAS REDES SOCIALES. UN ESTUDIO DE LAS DECISIONES DEL TEDH'
}

Freedom of expression, judicial independence, impartiality: the judges in social networks. A study of the rulings of the European Court of Human Rights

\author{
ENCARNACIÓN ROCA TRÍAS \\ Magistrada Tribunal Constitucional \\ eroca@tribunalconstitucional.es
}

Cómo citar/Citation

Roca Trías, E. (2021)

Libertad de expresión, independencia, imparcialidad: los jueces

en las redes sociales. Un estudio de las decisiones del TEDH.

Revista Española de Derecho Constitucional, 122, 13-45

doi: https://doi.org/10.18042/cepc/redc.122.01

\section{Resumen}

Uno de los problemas más discutidos en Europa en el momento actual se refiere a la libertad de expresión de los jueces. En el fondo de esta cuestión se encuentra la protección de la imparcialidad y la independencia de los jueces, como elemento indispensable del Estado de derecho. Desde 1982, con el caso Piersak, el Tribunal Europeo de Derechos Humanos ha tenido que tomar partido, formulando su canon sobre dos aspectos: el subjetivo y el objetivo. El ejercicio de la libertad de expresión puede comprometer ambos aspectos. Esto puede ser especialmente grave cuando la opinión del juez tiene lugar en las redes sociales, aunque los remedios no vayan a ser distintos de los tradicionales: el apartamiento del juez del caso mediante la abstención o la recusación. 


\title{
Palabras clave
}

Independencia judicial; libertad de expresión; redes sociales.

\begin{abstract}
One of the most discussed items among high Courts over Europe deals with the practice of Freedom of Expression by Judges. At the bottom of the discussion Judges impartiality and Independence protection is at the stake because both are considered as the main elements of the Rule of Law. From 1982 starting with Piersak case, the European Court of Human Rights took sides for the problem; the Court established its canon having in mind two aspects of the impartiality: the subjective and the objective. The practice of the Freedom of expression will affect both sides. The participation of judges in the social networks is specially discussed. But the remedies against the consequences of the lack of impartiality are always the same: challenge and abstention, the traditional remedies.
\end{abstract}

\section{Keywords}

Judicial independence; freedom of expression; social networks. 


\section{SUMARIO}

I. LA LIBERTAD DE EXPRESIÓN DE LOS JUECES: 1. Los textos internacionales referidos a la libertad de expresión de los jueces. 2. Las decisiones del TEDH. 3. Conclusiones de esta parte. II. EL EJERCICIO DE LA LIBERTAD DE EXPRESIÓN POR LOS JUECES: 1. Libertad de expresión e imparcialidad. 2. El ejercicio de la libertad de expresión por los jueces. 3. Jueces y redes sociales. 4. Independencia en las redes sociales. III. CONCLUSIONES. BibLIOGRAFía.

El Tribunal Europeo de Derechos Humanos tiene pendiente de resolver la moción 55603/18. De acuerdo con la cuestión formulada, debe decidir si «la amistad» en Facebook entre un juez y una de las partes de un proceso puede ser alegada como motivo de recusación. Se trata de la disputa por la custodia de una menor; la progenitora solicita la anulación de todos los actos procesales en los que había participado el expresidente de la APEA (Autoridad Suiza de Protección del Nińo y del Adulto), alegando que él y el padre de la niña eran «amigos en Facebook». De acuerdo con lo que dispone el art. 2.1 de la Convención Europea de Derechos Humanos (CEDH), el TEDH debe determinar si es compatible con la garantía de un juez imparcial la "amistad en Facebook» entre un juez y una de las partes. Según cuál sea la respuesta de la Corte, puede abrir una vía a la posibilidad de recusación a partir de la actividad de los jueces en las redes sociales.

De aquí que haya que enmarcar los problemas relativos a la independencia e imparcialidad del juez cuando está utilizando las redes sociales como un ciudadano más. De entrada, hay que decir que, en términos clásicos, la independencia judicial se centra en la imposibilidad de que los jueces reciban instrucciones para resolver los casos de cuya decisión están encargados. Los jueces no pueden recibir instrucciones del Poder Ejecutivo, y tampoco de otros tribunales o jueces. De este modo, distintas disposiciones en las constituciones de cada país se han ocupado de señalar que la independencia de los jueces tiene únicamente una excepción: su sujeción a la ley. La decisión del juez es la última norma del ordenamiento jurídico, y, por ello, la independencia va a significar la ausencia de todo tipo de subordinación, aunque esta va a ser siempre relativa porque, en todo caso, está sometido al ordenamiento jurídico (Requejo, 1989: 171). Creo que si la independencia puede tener un sentido positivo (independencia frente a instrucciones) y otro negativo, consistente en la intangibilidad de las resoluciones judiciales firmes, no puede verse afectada por los desatinos de las redes sociales ${ }^{2}$.

Cosa distinta es que las redes sociales puedan afectar a la imparcialidad del juez, y de eso voy a ocuparme aquí. Y parece lógico pensarlo, porque el juez puede perder su imparcialidad subjetiva si se pronuncia sobre asuntos de 
los que conozca o pueda conocer. Pero, además, puede verse afectada por los juicios paralelos que puedan aparecer en las redes sociales. Aquí están afectados los derechos fundamentales a la libertad de expresión y la libertad de información (art. $10 \mathrm{CEDH}$ ), pero, al mismo tiempo, atañe a la función básica del Estado de derecho concebido en términos constitucionales: la aplicación del derecho como mecanismo coercitivo de ordenación de la convivencia social. «La perturbación de esta función afecta a la estructura del poder en un Estado constitucional, pues priva de la imparcialidad a quien obligatoriamente ha de serlo y representa la intromisión de poderes e instancias carentes de legitimidad democrática».

Para opinar sobre estas cuestiones, deberían examinarse una serie de cuestiones que afectan a la independencia y, sobre todo, la imparcialidad de los jueces, aunque aquí voy a reflexionar básicamente sobre la extensión de su libertad de expresión, en cuanto que usuarios de las redes sociales, para llegar a la conclusión que parezca más correcta sobre el problema planteado. El tema no es tan simple que pueda limitarse a responder a la simple pregunta sobre la implicación de los jueces en las redes sociales.

\section{LA LIBERTAD DE EXPRESIÓN DE LOS JUECES}

Según la interpretación más ajustada, la imparcialidad de los jueces va ligada con la libertad de expresión. Según algunos autores, el derecho a la libertad de expresión es un «derecho de libertad, por lo que básicamente significa ausencia de interferencias o intromisiones de las autoridades estatales en el proceso de comunicación» (Bastida, 2018: 465). Y también significa «el reconocimiento y la garantía de una institución política fundamental, que es la opinión pública libre, indisolublemente ligada con el pluralismo político que es un valor fundamental y un requisito del funcionamiento del Estado democrático». Es por ello que la esfera de lo que se protege en el CEDH se refiere precisamente a la libertad de expresar opiniones. Incluye también la libertad de «recibir o comunicar informaciones o ideas» cuya publicación queda incluida en el derecho a la comunicación, con total exclusión de la censura previa. El TJUE ha utilizado un camino más complejo para llegar a la conclusión de que dentro de la UE rige la regla del Estado de derecho. Es decir, si los jueces son independientes del poder político de cada país, ello es porque en la UE rige el Estado de derecho, que incluye la independencia del Poder Judicial, y a partir de la sentencia Associação Sindical dos Juizes Portugueses (SASJP), ha abierto la vía para que puedan presentarse cuestiones 
prejudiciales relativas a leyes nacionales que se pueda entender que vulneran la independencia judicial.

Todos los ciudadanos son titulares del derecho a la libertad de expresión, y, en cuanto que ciudadanos, también los jueces, puesto que no existe restricción alguna en ningún texto constitucional. Es cierto que no existe ninguna disposición que directamente reconozca a los jueces la titularidad de su derecho a expresarse libremente; lo contrario sí existe, en tanto que el art. 10.2 in fine $\mathrm{CEDH}$ incluye entre los límites al ejercicio de la libertad de expresión en general la "garantía de la autoridad y la imparcialidad del poder judicial», y también estaría implícitamente recogida en el art. 20.4 CE. Pero este no es el objeto de este estudio. También es cierto que en los ordenamientos occidentales la problemática de la libertad de expresión de los jueces se ha reconducido a las causas de abstención y recusación recogidas en España en el art. 219 LOPJ. A partir de aquí, un elemento importante de defensa del Estado de derecho se planteará en torno a la independencia de los jueces. ¿Forma parte del Estado de derecho la independencia del Poder Judicial? De lo dicho en la STJUE de 27 de febrero de 2018, en el asunto Associaçao Sindical dos Juizes Portugueses (SASJP), se abre una puerta al control directo por parte de la UE del cumplimiento del derecho de la UE y se determina que el contenido del Estado de derecho en la UE es el previsto en el art. 19 TUE, que establece el Tribunal de Justicia, que "garantizará el respeto del Derecho en la interpretación y aplicación de los Tratados» e impone a los Estados miembros la obligación de establecer "las vías de recurso necesarias para garantizar la tutela judicial efectiva en los ámbitos cubiertos por el Derecho de la Unión». La independencia judicial será inherente a la función de juzgar, según la citada sentencia: «La existencia misma de un control judicial efectivo para garantizar el cumplimiento del Derecho de la Unión es inherente a un Estado de Derecho» (\$36), y a continuación ańade: «A efectos de garantizar la tutela judicial efectiva, resulta primordial preservar la independencia de tal órgano, como así lo confirma el artículo 47, párrafo segundo, de la Carta, precepto que, entre las exigencias vinculadas al derecho fundamental a la tutela judicial efectiva, menciona el acceso a un juez independiente» $(\$ 42)$. Pero no hay que olvidar que "[l]a garantía de independencia, que es inherente a la misión de juzgar no sólo se impone, en el ámbito de la Unión, en lo que respecta a los jueces y abogados generales del Tribunal de Justicia y a los jueces del Tribunal General, tal como prevé el artículo 19 TUE, apartado 2, párrafo tercero, sino que también obliga, en el ámbito de los Estados miembros, en lo que respecta a los jueces y tribunales nacionales». Y todo ello en cumplimiento de lo establecido en el art. 47.2 de la Carta de Derechos Fundamentales de la UE, que incluye 
como un elemento de la tutela judicial efectiva que las causas deben ser decididas por un «juez independiente e imparcial». Así, la imparcialidad del juez se constituye como un elemento integrador del Estado de derecho, y, por ello, a partir de la sentencia citada, y en otros casos sobre imparcialidad judicial relacionados con Polonia y Hungría, que, para no alargar este texto, no van a ser objeto de estudio ${ }^{3}$.

Para construir un cierto núcleo teórico de la libertad de expresión de los jueces, hay que examinar qué se dice en los textos internacionales sobre conducta judicial. Los llamados «Principios Éticos para Jueces y Magistrados» suelen incluir el principio de la imparcialidad, juntamente con el de la independencia. Sin independencia no hay imparcialidad, cierto, pero, así como la primera está integrada en el estatuto judicial como consecuencia de la separación de poderes ínsita en un Estado de derecho moderno, la segunda es una consecuencia de la primera y se refiere a la actuación del juez en relación con los asuntos de que debe conocer y se extiende, a mi parecer, a los asuntos que están pendientes en los juzgados y tribunales. Se considera que se trata de una apariencia: el juez no solo debe ser imparcial, sino, además, aparecer como tal. Pero creo que es algo más, porque, en definitiva, hay que preservar la división de poderes $y$, dentro de ella, la independencia judicial en su aspecto relativo a la imparcialidad. La actuación de los jueces tiene consecuencias importantísimas, ya que el Poder Judicial no está encerrado en sí mismo, sino que se proyecta en la sociedad, teniendo en sus manos el control de los actos del Ejecutivo. Lo que, además, se refleja de forma aún más importante en los tribunales constitucionales, encargados de velar por la pureza constitucional del ordenamiento y, en consecuencia, de la corrección de las decisiones tomadas por el Poder Legislativo.

Muy posiblemente sean estas las razones que han llevado a diferentes grupos a elaborar propuestas sobre la aplicación de estos diferentes principios a los jueces, de momento, soft law, que, sin embargo, tienen una cierta vocación de generalidad en el sentido de que, por una parte, se inspiran en decisiones de tribunales internacionales, como el TEDH, y, por otra, se pretende que se conviertan en principios que ayuden a la toma de decisiones en cuestiones relacionadas con la imparcialidad de jueces y magistrados.

3 Véanse las SSTJUE Minister of Justice and Equality, de 25 de julio de 2018; Comisión c. Polonia, fundamental, de 24 de junio de 2019; $A$. K, de 19 de noviembre de 2019, y Comisión Europea c. Polonia, de 5 de noviembre de 2019. 


\section{LOS TEXTOS INTERNACIONALES REFERIDOS A LA LIBERTAD DE EXPRESIÓN DE LOS JUECES}

a) Los textos internacionales proclaman que toda persona tiene derecho a ser oída por un tribunal independiente e imparcial ${ }^{4}$. Lo que aquí interesa son las disposiciones del Convenio Europeo de Derechos Humanos, de 1950, que contiene dos normas fundamentales respecto de lo que se está discutiendo en este trabajo y que son las que aplica el TEDH en las sentencias que examinaré. Se trata del art. 6.1 CEDH, que establece:

Toda persona tiene derecho a que su causa sea oída de manera equitativa, públicamente y dentro de plazo razonable, por un tribunal independiente e imparcial [énfasis añadido] establecido por la ley, que decidirá los litigios sobre sus derechos y obligaciones de carácter civil o sobre el fundamento de cualquier acusación en materia penal dirigida contra ella.

Asimismo, y en lo relativo a la libertad de expresión, el artículo fundamental es el $10 \mathrm{CEDH}$, que establece:

1. Toda persona tiene derecho a la libertad de expresión. Este derecho comprende la libertad de opinión y la libertad de recibir o de comunicar informaciones o ideas, sin que pueda haber injerencia de autoridades públicas y sin consideración de fronteras. El presente artículo no impide que los Estados sometan a las empresas de radiodifusión, de cinematografía o de televisión a un régimen de autorización previa.

2. El ejercicio de estas libertades, que entrañan deberes y responsabilidades, podrá ser sometido a ciertas formalidades, condiciones, restricciones o sanciones previstas por la ley, que constituyan medidas necesarias, en una sociedad democrática, para la seguridad nacional, la integridad territorial o la seguridad pública, la defensa del orden y la prevención del delito, la protección de la salud o de la moral, la protección de la reputación o de los derechos ajenos, para impedir la divulgación de informaciones confidenciales o para garantizar la autoridad y la imparcialidad del poder judicial.

4 Así, el art. 19 de la Declaración Universal de Derechos Humanos, de Naciones Unidas, de 10 de diciembre de 1948, y el art. 14.1 del Pacto Internacional de Derechos Civiles y Políticos, de 16 de diciembre de 1966. 
b) Soft law ${ }^{5}$. Seguramente el texto más importante lo constituyen los Principios de Bangalore sobre la conducta judicial ${ }^{6}$, en general. Una de las razones que llevaron a la redacción de estos principios fue que «una judicatura de integridad inobjetable» ofrece al público «un baluarte contra los atropellos a los derechos y libertades garantizados por la ley». Por ello en el año 2000 se crea un Grupo Judicial de Reforzamiento de la Integridad Judicial que en sus trabajos va desarrollando unos principios básicos que, finalmente, han sido adoptados por algunos Estados, y otros han adaptado sus reglas de conducta al texto. Nacen como una decisión del Centro de Naciones Unidas sobre prevención del delito y tratamiento del delincuente de elaborar unos principios que tuvieran un carácter universal, dado el "problema creado por le evidencia de que en muchos países de todos los continentes mucha gente perdía la confianza en sus sistemas judiciales debido a que se les percibía como corruptos o parciales». Por ello se añade que Naciones Unidas invitó a jueces a «elaborar un concepto de responsabilidad judicial que complementase el principio de independencia judicial y elevara con ello el nivel de confianza del público en el imperio de la ley»?. El texto desarrolla los principios de la Declaración Universal de Derechos Humanos, de 1948, y tiene como función determinar reglas de conducta, a fin de garantizar no solo el contenido de la independencia judicial, sino la apariencia de imparcialidad e independencia, sobre la base de la garantía de toda persona a ser juzgada por un tribunal «competente, independiente e imparcial $»^{8}$.

5 El preámbulo del texto Principios de ética judicial, aprobado en 2016 por el CGPJ, hace referencia a los textos siguientes: Principios de Bangalore (2001), en el marco de Naciones Unidas; Dictamen del Consejo Consultivo de los Jueces europeos del Consejo de Europa sobre la ética y la responsabilidad de los jueces (2002); el Código Modelo Iberoamericano de ética judicial (2006), adoptado por la Cumbre Judicial Iberoamericana, al que se adhirió el CGPJ en 2016, y la Declaración de Londres sobre la deontología de los jueces (2010).

6 The Bangalore Principles of Judicial Conduct (ECOSOC Resolution 2006/23). Las citas se han tomado del comentario relativo a los Principios de Bangalore sobre la conducta judicial. (2013), pp. iii y iv. Este texto ha sido reconocido por la American Bar Association, la Comisión Internacional de Juristas y los miembros del Consejo de Europa. Comentario cit., p. 1, «Historia de la redacción. Antecedentes».

8 Los propios principios reconocen que "pretenden establecer estándares para la conducta ética de los jueces. Están formulados para servir de guía a los jueces y para proporcionar a la judicatura un marco que regule la conducta judicial [...]. Estos principios presuponen que los jueces son responsables de su conducta frente a las instituciones correspondientes establecidas para mantener los estándares judiciales, que dichas instituciones son independientes e imparciales y que tienen como objetivo 
Voy a referirme a continuación a algunos «principios»o "valores» que son consecuencia del ejercicio por parte del juez de su libertad de expresión. En el «valor» 2 se dice que «la imparcialidad es esencial para el desempeño correcto de las funciones jurisdiccionales. La imparcialidad se refiere no solo a la decisión en sí misma, sino también al proceso mediante el cual se toma esa decisión», y en desarrollo del principio, se añade en el comentario que «un juez deberá desempeñar sus tareas judiciales sin favoritismo, predisposición o prejuicio»?. En el valor 4, Corrección, se formula el siguiente principio: «La corrección y la apariencia de corrección son esenciales para el desempeño de todas las actividades de un juez». Y en el comentario subsiguiente, se afirma: «Lo que más importa no es lo que el juez hace o no hace sino lo que los demás piensan que el juez ha hecho o puede hacer». Dentro de este principio, se incluyen diversas reglas de "aplicación», entre las que se encuentra la libertad de expresión, que se formula de la siguiente forma:

4.6. Un juez, como cualquier otro ciudadano, tiene derecho a la libertad de expresión y de creencias, derecho de asociación y reunión per, cuando ejerza los citados derechos y libertades, se comportará siempre de forma que preserve la dignidad de las funciones jurisdiccionales y la imparcialidad e independencia de la judicatura.

En el comentario a este «valor» se señala de forma clara que, por el hecho de acceder a la judicatura, los jueces no renuncian a sus derechos a la «libertad de expresión, asociación y reunión» de que gozan las demás personas, ni dejan de tener ideas políticas. Sin embargo, se añade que «se necesita moderación para mantener la confianza del público en la imparcialidad e independencia de la judicatura». El juez puede intervenir en los debates públicos, aunque «no debe tomar parte de modo inapropiado en polémicas públicas», y aunque puede hablar de asuntos que afecten a la judicatura, como el funcionamiento de los tribunales, la independencia, etc., debe hacerlo «con gran circunspección». Esta es una cuestión importante, que ha sido tratada en algunos asuntos por el TEDH, como veremos a continuación.

complementar y no derogar las normas legales y de conducta existentes que vinculan a los jueces» (comentario cit., p. 29).

9 Entendiéndose por "predisposición» «una simpatía, preferencia o favoritismo hacia una u otra parte o hacia un resultado determinado», lo que en materia jurisdiccional significa "una inclinación a decidir una cuestión o fallar una causa de cierta manera que no deja la mente judicial plenamente abierta al convencimiento» (comentario cit., p. 55). 
El Consejo de Derechos Humanos de Naciones Unidas ${ }^{10}$, en el informe del relator general sobre independencia de jueces y abogados, presentado en 2019, en el apartado IV, sobre la «libertad de expresión», n. ${ }^{\circ} 33$, señala que «los jueces y fiscales tienen un deber de lealtad, reserva y discreción con respecto a su empleador, y se espera que actúen con moderación en el ejercicio de su libertad de expresión en todos los asuntos en los que sea probable que se cuestionen la autoridad y la imparcialidad de la judicatura", y cita sentencias del TEDH, a las que luego me referiré. Especialmente interesante es el caso Baka c. Hungría, de 23 de junio de 2016.

El Consejo Consultivo de los Jueces Europeos aprobó en 2010 lo que se denomina Magna Carta of Judges (Fundamental Principles), en la que después de recordar en el principio 1 que el Poder Judicial es uno de los tres poderes de un Estado democrático, tiene como misión garantizar la existencia del Estado de derecho y, en consecuencia, asegurar la correcta aplicación del derecho de una forma imparcial, justa y eficiente, señala en el principio 2 que la independencia judicial y la imparcialidad son requisitos esenciales en toda operación judicial, para acabar asegurando que los principios deontológicos, distintos de las normas sancionadoras, deben guiar las acciones de los jueces (principio 18). No hay referencias a la libertad de expresión, aunque está implícito al hablar de la independencia y la imparcialidad ${ }^{11}$.

En Espańa, los Principios de Ética Judicial, aprobados por el Consejo General del Poder Judicial en $2016^{12}$, no se pronuncian directamente sobre la libertad de expresión de jueces y magistrados. Sin embargo, el principio 19 dice:

En su vida social y en su relación con los medios de comunicación el juez y la jueza pueden aportar sus reflexiones y opiniones, pero a la vez deben ser prudentes para que su apariencia de imparcialidad no quede afectada con sus declaraciones públicas, y deberán mostrar, en todo caso, reserva respecto de los datos que puedan perjudicar a las partes o al desarrollo del proceso.

El dictamen más significativo es el de 14 de enero de $2021^{13}$; se responde a la consulta sobre «si la imagen de un juez puede verse afectada en una parti-

10 Naciones Unidas. Asamblea General. Consejo de Derechos Humanos, 41 período de sesiones, de 24 de junio a 12 de julio de 2019. Tema 3 de la agenda. Independencia de los magistrados y abogados. Informe del relator especial sobre la independencia de los magistrados y abogados. Distribuido el 29 de abril de 2019.

11 Véase www.coe.int/ccje.

12 Véase https://bit.ly/3h2rRgq.

13 Dictamen (Consulta 4/2020) de 14 de enero de 2021. Poderjudicial.es. 
cipación pública entendida en sentido amplio», como una entrevista en un medio de comunicación, una intervención en redes sociales o incluso un coloquio jurídico. Con cita de muchos de los documentos a que se hace referencia en este trabajo, la conclusión de la Comisión de Ética Judicial del CGPJ concluye que las intervenciones de los jueces en este tipo de foros «deben ajustarse al concepto de neutralidad política que impregna los principios de imparcialidad, independencia e integridad" y que deben actuar con "prudencia y moderación», que son "las dos actitudes sobre las que pivota la libertad de expresión del juez o Magistrada tanto en los principios del Código ético español, como en el ámbito internacional», así como actuar con un trato respetuoso y «demandar una información suficiente sobre el funcionamiento de las redes sociales o cualesquiera otras plataformas de uso social y sobre el uso de las mismas».

De aquí que se puede llegar a una primera conclusión: libertad de expresión sí, pero prudentemente ejercitada.

\section{LAS DECISIONES DEL TEDH}

La mayoría de los textos internacionales y nacionales a que he hecho mención tienen como base diversas sentencias del TEDH. A ellas me voy a referir a continuación.

He puesto de relieve, y ahora vuelvo a recordarlo, que todos los ciudadanos son titulares del derecho a la libertad de expresión, y, en consecuencia, los jueces también, puesto que no existe ninguna restricción en ningún texto constitucional y su condición de jueces no puede hacerles de peor condición con respecto a la titularidad de sus derechos fundamentales.

A partir de esta afirmación, hay que examinar cómo se han interpretado estos derechos en las sentencias del TEDH, puesto que los textos internacionales sobre conducta judicial, a los que me he referido en el anterior apartado, incluyen los principios de imparcialidad e independencia, partiendo del ejercicio por los jueces de la libertad de expresión. Sin independencia no hay imparcialidad, cierto, pero, así como la primera está integrada en el estatuto judicial como consecuencia de la separación de poderes ínsita en un Estado de derecho moderno, la segunda es una consecuencia de la primera y se refiere a la actuación del juez en relación con los asuntos de que debe conocer y se extiende a los que están pendientes en los juzgados y tribunales. Se trata también de una apariencia: el juez no solo debe ser imparcial, sino, además, debe aparecer como tal.

a) Uno de los casos más antiguos sobre independencia e imparcialidad de un juez en el TEDH es el caso Piersak c. Bélgica, de 1 de octubre de 1982. 
Hay que resaltar que no se trata exactamente de un caso relativo a la libertad de expresión de los jueces, como algunos de los que se tratarán a continuación, pero es importante hacer una referencia porque determina de forma muy clara la distinta apreciación de los aspectos objetivo y subjetivo de la independencia del tribunal, de acuerdo con lo dispuesto en el art. 6.1 CEDH. El demandante había cuestionado que se hubiese aplicado el art. 6.1 CEDH al no haber sido juzgado, a su parecer, por un tribunal «independiente, imparcial y establecido por la ley», ya que entre los miembros del tribunal se encontraba un «fiscal» que había intervenido anteriormente en el caso. El $\$ 30$ de dicha sentencia distingue entre la independencia subjetiva y la objetiva del juzgador, llegando a la conclusión de que no es suficiente que concurra el primer aspecto, el subjetivo, sino que debe acompañarse del segundo. Después de decir que nadie duda de la imparcialidad personal del juez en cuestión y que «el simple hecho de que un juez haya sido miembro del Ministerio Público no es razón suficiente para temer que carece de imparcialidad», cosa con la que el Tribunal coincide, el TEDH añade:

En orden a que los tribunales puedan inspirar la confianza que es indispensable, es preciso tener en cuenta un criterio de carácter orgánico. Si una persona, después de haber ocupado un departamento del Ministerio Público cuya naturaleza es tal que deba tratar un determinado asunto en razón de sus competencias y posteriormente debe conocer el mismo caso como juez, los ciudadanos tienen el derecho a temer que no ofrezca las suficientes garantías de imparcialidad.

Que es lo que ocurrió en el caso que se juzgaba, lo que llevó al TEDH a estimar el recurso presentado, por entender que se había producido una violación del art. 6.1 CEDH en lo relativo a la imparcialidad.

b) Hay algunos casos en los que el TEDH reconoce que se ha producido una lesión directa del derecho a la libertad de expresión de los jueces. Uno de los más interesantes es el caso Wille c. Liechstenstein, de 20 de octubre de 1999. Se planteó una discrepancia entre el demandante y el príncipe de Liechtenstein sobre las funciones del Tribunal Constitucional de aquel país en relación con la interpretación de la Constitución; dicha discrepancia proviene de una conferencia pronunciada por el demandante en un ciclo de conferencias organizadas por la universidad sobre la Constitución. A raíz de este hecho, el príncipe le dirigió una carta en la que expresaba su desacuerdo sobre la cuestión política planteada en la citada conferencia y le manifestó que creía que no estaba vinculado por la Constitución y, en consecuencia, que no era apto para desempeñar funciones públicas. Por estas razones añadía que se negaría a 
nombrarle para cualquier cargo si fuese propuesto. El demandante era en aquel momento presidente del Tribunal Administrativo Central, por tiempo determinado. A esta carta, el demandante respondió que el príncipe vulneraba su derecho a la libertad de expresión. En 1997 se produjo el hecho que causó el recurso: la dieta propuso la renovación y el príncipe se negó a confirmar el nombramiento. El demandante alegó ante el TEDH la vulneración de su derecho a la libertad de expresión y la libertad de cátedra, pero, finalmente, el Tribunal acogió la reclamación fundada en la vulneración del art. $10 \mathrm{CEDH}$ :

Para apreciar si la medida adoptada por el Príncipe en reacción a la declaración hecha por el demandante respondía a una «necesidad social apremiante» y era "proporcionada al fin legítimo perseguido», el Tribunal debe examinar a la luz del caso en su conjunto otorgando especial importancia al cargo desempeñado por el demandante, a su declaración, a las circunstancias en las que se formuló y a la reacción que provocó.

El Tribunal observa que el demandante era, en la época de los hechos, un magistrado de alto rango. El Tribunal estima que cuando la libertad de expresión de personas que ocupan tales cargos se encuentra en juego, los «deberes y responsabilidades» contemplados en el artículo 10.2 revisten una importancia particular; en efecto, cabe esperar de los funcionarios del orden jurisdiccional que muestren cierta mesura en el ejercicio de su libertad de expresión en todos los casos en donde la autoridad y la imparcialidad del poder judicial puedan ser puestas en entredicho. No obstante, el Tribunal estima que cualquier vulneración de la libertad de expresión de un magistrado en la situación del demandante exige de su parte un escrutinio minucioso.

La opinión expresada por el demandante no puede calificarse de proposición indefendible, puesto que es compartida por un número considerable de personas en Liechtenstein. Por otra parte, no podría afirmarse que durante la conferencia el demandante comentara casos en curso, criticara duramente a personas o instituciones públicas, o injuriase a altos funcionarios o al Príncipe.

De ahí el TEDH concluye que la injerencia en la libertad de expresión del demandante «no era necesaria en una sociedad democrática», aplicando el art. 10.2 CEDH, por lo que estima el recurso.

c) El caso Wille c. Liechtenstein es un caso puro de inmisión en el ejercicio de la libertad de expresión de un poder público, un juez, realizada por otro poder público, el jefe del Estado. No se encuentran casos tan claros, aunque existen otros interesantes relativos a la libertad de expresión de los jueces. El caso Pitkevich c. Rusia, de 8 de febrero de 2001, tiene por objeto la 
violación del art. 10.2 CEDH. Se trataba de una jueza que pertenecía a la Unión de las Iglesias Evangélicas de Rusia. Fue acusada de interferir con sus creencias religiosas y ello supuso la iniciación de un expediente disciplinario con la consecuencia de su cese como jueza por haber dañado su reputación. Después de las actuaciones procesales correspondientes, presentó la demanda ante el TEDH, reclamando, en lo que aquí interesa, que se había vulnerado su libertad de expresión. El TEDH utiliza aquí su método habitual, es decir, en primer lugar examina si el derecho cuya violación se reclama quedó afectado por las decisiones de las autoridades judiciales que llevaron a cabo el expediente sancionador $y$, una vez que se comprueba que ha existido la afectación, como ocurre en este caso ${ }^{14}$, pasa a examinar si concurre alguna de las causas que de acuerdo con el art. 10.2 $\mathrm{CEDH}$ permiten concluir que no se produjo una vulneración del derecho, por constituir medidas necesarias en una sociedad democrática. Debe recordarse que una de las causas que llevó a la decisión de expulsión de la demandante del cuerpo judicial fue la interferencia de sus creencias religiosas con su actividad como jueza.

Los argumentos del TEDH se centran: i) en el papel prominente que el juez tiene en una sociedad democrática ${ }^{15}$, y ello aunque no sea funcionario público; ii) que resulta probado que la jueza había ${ }^{16}$ hecho diversas referencias a la moralidad de las partes en diversos casos, lo que significa una apariencia de parcialidad; iii) la penalización de la reclamante afectó únicamente a su actividad como jueza y no a su vida privada, en la que podía expresarse libremente, y iv) las actividades probadas interfirieron con su actuación como jueza ${ }^{17}$, porque había promovido la fe religiosa en la que creía por delante de

14 La sentencia dice: «That the applicant was dismissed for her specific activities while performing her judicial functions, whereby she expressed her religious views. In this regard there has been an interference with the applicant's freedom of religion or freedom of expression», de acuerdo con los arts. 9 y $10 \mathrm{CEDH}$, aunque ello no llevará al TEDH a estimar la reclamación (pág. 12 de STEDH Pitkevich c. Rusia).

15 "Given the prominent place among State organs which is occupied by the judiciary in a democratic society, the Court considers that this is particularly so in case of restriction on freedom of expression of a judge in connection with the performance of his functions, albeit the judiciary is not part of the ordinary civil service».

16 "The Court considers that an opinion by a judge concerning the morality of a party may justify an appearance of bias by the judge, unless the opinion was necessary to resolve the case and substantiate the judgment».

17 "On the basis of those facts it was concluded that the applicant had intimidated parties to proceedings in court, and that she had promoted the Church in damage of the State interest to protect the rule of law. As a result the applicant called into question her impartiality and impaired the authority of the judiciary. In these 
los intereses del Estado en la implementación del Estado de derecho. En el fondo de la sentencia late un problema de colisión entre la imparcialidad del juez y el derecho a su libertad de expresión de sus creencias religiosas. En la ponderación que efectúa el TEDH se parte de la preponderancia de los intereses del Estado, ya que afectan a todos los ciudadanos, que no deben soportar que las decisiones judiciales sean interceptadas por las creencias religiosas del propio juez. Así, el principio 6.1 de los de Bangalore va a exigir al juez que las obligaciones judiciales primen sobre todas sus demás actividades, lo que incluye también el ejercicio de sus derechos religiosos, según decide el TEDH en la sentencia a que se hace referencia.

d) En el caso Kayasu c. Turquía, de 13 de noviembre de 2008, un fiscal, el Sr. Kayasu, a título particular, interpone una querella contra cinco exgenerales del ejército, autores de un golpe de Estado contra la República de Turquía, que no habían sido condenados, porque lo impedía la norma constitucional entonces en vigor. Se inicia un procedimiento sancionador contra Kayasu por haber desconocido la norma constitucional. El Consejo Superior de la Magistratura le impuso una sanción disciplinaria por haber ofendido el honor de estos militares. Siguieron una serie de procedimientos, hasta que finalmente Kayasu fue condenado. Hay que tener en cuenta, además, que el demandante había entregado los documentos a la prensa, lo que le produjo nuevas condenas. El TEDH consideró que se había producido una infracción del art. 10 del Convenio, utilizando algunos argumentos que también van a aparecer en diversos documentos de los examinados en el anterior apartado. Así, comienza diciendo que de lo sucedido se deduce que el demandante había sufrido injerencias en su derecho a la libertad de expresión porque había sufrido dos condenas, una en el ámbito penal y otra, en el disciplinario. Dicho esto, pasa al examen del cumplimiento de los requisitos establecidos en el art. 10.2 $\mathrm{CEDH}$. Las sanciones deben estar previstas en la ley y llega a la conclusión de que sí lo estaban $(\$ 86)$ y que respondían a una de las finalidades previstas en el art. 10.2 $\mathrm{CEDH}^{18}$. Pero ello no es suficiente, porque debe comprobarse

circumstances, and allowing for a certain margin of appreciation in this respect, the Court finds that the reasons adduced by the authorities in this case were "sufficient" for the interference with the applicant's rights under Article 10 of the Convention".

18 «La Cour rappelle également que la portée de la notion de prévisibilité dépend dans une large mesure du contenu du texte dont il s'agit, du domaine qu'il couvre ainsi que du nombre et de la qualité de ses destinataires. La prévisibilité de la loi ne s'oppose pas à ce que la personne concernée soit amenée à recourir à des conseils éclairés pour évaluer, à un degré raisonnable dans les circonstances de la cause, les conséquences pouvant résulter d'un acte déterminé. Il en va spécialement ainsi des professionnels, 
también si constituyen «medidas necesarias en una sociedad democrática». Y ahí el TEDH, después de resumir su propia jurisprudencia $(\$ 88)$, y citando el caso Wille, considera que todo atentado a la libertad de expresión de un juez debe ser examinado de forma cuidadosa y caso por caso $(\$ 92)$. Aunque el propósito del reclamante fue el de llamar la atención sobre unos hechos que consideraba constitutivos de delito, como un golpe de Estado, recordaba que no se debería utilizar la prensa ${ }^{19}$. Dicho esto, consideró el TEDH que las condenas penal y disciplinaria a un funcionario de la Administración de justicia tienen un efecto disuasorio sobre el propio funcionario y sobre la profesión en su conjunto, lo que sería contrario a la confianza en la Administración de justicia ${ }^{20}$.

e) Los casos sobre vulneración de la libertad de expresión de un juez tienen como motivo general la afirmación de que los jueces gozan de dicho derecho fundamental. Así vuelve a repetirse en el caso Kudeshkina c. Rusia (26 de febrero de 2009). A raíz de unos procedimientos penales, que sería largo relatar, dada la complejidad de las reglas de procedimiento, la demandante había sido apartada del procedimiento debido a su conducta y por ello se entendió que debía finalizar en el ejercicio de su cargo. La reclamante pidió que se protegiera su libertad de expresión ya que había realizado unas declaraciones a la prensa en el curso de una campaña electoral en la que se presentaba como candidata. El TEDH, usando su método habitual, consideró que la sanción disciplinaria había interferido en el derecho a la libertad de expresión de la reclamante $y$, a continuación, examina si se cumplen los requisitos y circunstancias de las excepciones contenidas en el art. 10.2 CEDH, que permitirían desestimar la demanda. Pero ello no ocurre en el caso Kudeshkina. En efecto, i) el TEDH se fija en la interpretación de la expresión «medidas necesarias en una sociedad democrática» y considera que el funcionamiento

habitués à devoir faire preuve d'une grande prudence dans l'exercice de leur métier ; aussi peut-on attendre d'eux qu'ils mettent un soin particulier à évaluer les risques qu'il comporte» (\$85).

19 «La Cour rappelle que la plus grande discrétion s'impose aux autorités judiciaires. Cette discrétion doit les amener à ne pas utiliser la presse, même pour répondre à des provocations» (\$100).

20 «Pour avoir confiance dans l'administration de la justice, le public doit avoir confiance en la capacité des magistrats à représenter effectivement les principes de l'état de droit. Il s'ensuit que cet effet dissuasif est un facteur important à prendre en compte pour ménager un juste équilibre entre le droit à la liberté d'expression d'un magistrat et tout autre intérêt légitime concurrent dans le cadre d'une bonne administration de justice» $(\$ 106)$. 
de la justicia es necesario en una sociedad democrática ${ }^{21}$; ii) al interpretar la frase del art. 10.2 CEDH referida a la garantía de la autoridad y la imparcialidad del Poder Judicial, la sentencia permitiría limitar la libertad de expresión del juez, siempre que se tenga en cuenta que el funcionamiento de la justicia pertenece al ámbito del interés público del Estado, y para garantizar el buen funcionamiento, se permite el límite a la libertad de expresión del juez (\$93). Finalmente, en su método habitual se examina la proporcionalidad de la sanción acordada, considerando que podría producir un chilling effect (\$98), cosa en la que insisten las sentencias del TEDH.

f) La sentencia Olujić c. Croacia, de 5 de febrero de 2009, presenta un caso de independencia de los miembros de un tribunal que habían opinado sobre unas denuncias de pederastia al presidente del Tribunal Supremo, que finalmente fue cesado como presidente y como juez. Este presentó la demanda alegando violación del art. 6.1 CEDH. Con respecto a la imparcialidad de los tres miembros del Consejo, el Tribunal recuerda los principios mantenidos en decisiones anteriores $(\$ \$ 56-57)^{22}$ : i) la imparcialidad consiste en la ausencia de prejuicio o de parcialidad; ii) desde el punto de vista subjetivo, existe una presunción de imparcialidad, que puede ser destruida por cualquier tipo de prueba; iii) pero cuando un juez ha pronunciado determinadas opiniones en

21 "The Court reiterates that issues concerning the functioning of the justice system constitute questions of public interest, the debate on which enjoys the protection of Article 10. However, the Court has on many occasions emphasised the special role in society of the judiciary, which, as the guarantor of justice, a fundamental value in a law-governed State, must enjoy public confidence if it is to be successful in carrying out its duties. It may therefore prove necessary to protect that confidence against destructive attacks which are essentially unfounded, especially in view of the fact that judges who have been criticised are subject to a duty of discretion that precludes them from replying (see Prager and Oberschlick v. Austria, 26 April 1995, $\$ 34$, Series A no. 313). The phrase "authority of the judiciary" includes, in particular, the notion that the courts are, and are accepted by the public at large as being, the proper forum for the settlement of legal disputes and for the determination of a person's guilt or innocence» $(\$ 86)$.

22 "First and foremost, it is of fundamental importance in a democratic society that the courts inspire confidence in the public and above all, as far as criminal proceedings are concerned, in the accused Impartiality normally denotes absence of prejudice or bias and its existence can be tested in various ways. The Court has thus distinguished between a subjective approach, that is endeavouring to ascertain the personal conviction or interest of a given judge in a particular case, and an objective approach, that is determining whether he or she offered sufficient guarantees to exclude any legitimate doubt in this respect». 
relación con los casos que tiene entre manos se destruye la presunción de imparcialidad $^{23}$. Finalmente, el TEDH declaró que había habido una vulneración del derecho reconocido en el art. 6.1 CEDH.

g) En el caso Di Giovanni c. Italia, de 9 de marzo de 2013, plantea dos supuestos: el de la imparcialidad de los jueces instructores de un expediente disciplinario en el seno del Consiglio Superiore della Magistratura (CSM), con denuncia de violación del art. 6.1 CEDH y la del art. $10 \mathrm{CEDH}$, sobre la libertad de expresión del juez. Una magistrada publicó unas declaraciones en la prensa sobre el funcionamiento del CSM italiano; el CSM abrió diligencias y le impuso una sanción; la magistrada recurrió ante el TEDH. Por lo que respecta a la imparcialidad e independencia del órgano disciplinario, que el TEDH equipara a un tribunal, el Tribunal aplica los criterios habituales en el sentido de que considera i) que para decidir sobre esta cuestión deben tenerse en cuenta la modalidad de la designación de los miembros del CSM, la duración del mandato y la tutela contra presiones externas establecida en las leyes reguladoras del CSM; ii) que hay que tener en cuenta los aspectos subjetivo y objetivo de la imparcialidad, considerando que "el elemento determinante consiste en acertar si los temores del interesado pueden considerarse objetivamente justificados» (\$55), y iii) que la pertenencia a corrientes ideológicas distintas internas no forma parte de la dependencia jerárquica. Por todo ello, no se admitió a trámite la vulneración del art. $6 \mathrm{CEDH}$.

Por lo que respecta a la alegada vulneración del art. $10 \mathrm{CEDH}$, el Tribunal considera que las medidas tomadas contra la jueza no fueron desproporcionadas, por lo que no se había producido la vulneración que se alegaba.

h) La sentencia más significativa, que, además, refleja toda la problemática sobre independencia de jueces y magistrados por nombramientos manipulados por los Gobiernos de Hungría y Polonia, es la sentencia Baka c. Hungría, decidida por la Grand Chambre el 23 de junio de 2016. A diferencia de los casos resueltos por el TJUE, que solo de una forma indirecta se refieren a la protección del derecho a expresarse libremente, puesto que su principal motivo se refiere a la independencia del Poder Judicial, la sentencia Baka afronta directamente la vulneración de la libertad de expresión del

23 «Thus, where a court president publicly used expressions which implied that he had already formed an unfavourable view of the applicant's case before presiding over the court that had to decide it, his statements were such as to justify objectively the accused's fears as to his impartiality (see Buscemi v. Italy, cited above, \$68). On the other hand, in another case, where a judge engaged in public criticism of the defence and publicly expressed surprise that the accused had pleaded not guilty, the Court approached the matter on the basis of the subjective test». 
demandante, presidente de la Corte Suprema húngara. A semejanza de lo que había ocurrido en la sentencia Wille, el juez Baka había manifestado unas opiniones contrarias a la reforma del sistema judicial en Hungría; aprobada la reforma, el mandato del juez Baka acabó tres años y medio antes de lo previsto en su nombramiento, porque la nueva ley reguladora de la función judicial acortó la edad de jubilación, lo cual significó la pérdida de beneficios tales como seguridad social, casa habitación a cargo del Estado, y otros. El caso había sido decidido antes en la STJUE Comisión c. Hungría, de 6 de noviembre de $2012^{24}$, no desde el aspecto de la vulneración de los derechos del reclamante, y había sido objeto de diversas declaraciones de distintos órganos internacionales y europeos, siempre en contra de la decisión del Gobierno húngaro. El problema principal que se le plantea al TEDH se refiere al ejercicio de la libertad de expresión por parte del demandante, porque en su reclamación el juez había manifestado que la reducción de su mandato se debió a las críticas expresadas en contra de la reforma de la judicatura. En primer lugar, el TEDH considera que existe una interferencia en el derecho a la libertad de expresión del juez, no necesaria en una sociedad democrática, y que en cada caso de los examinados por el Tribunal hay que tener en cuenta sus circunstancias (\$\$ 141-142); de ello deduce que la secuencia de los hechos estudiados determina que ha existido una relación de causalidad entre el ejercicio de la libertad de expresión y la finalización del mandato del juez $(\$ \$ 148$ y 151). Luego, ha de examinarse si esta interferencia resultaba justificada en alguno de los casos previstos en el art. 10.2 CEDH y su conclusión es negativa por las siguientes razones: i) aunque se pueden cambiar las reglas reguladoras de la función judicial, ello debe obedecer a una finalidad de reforzar la independencia de los jueces ${ }^{25}$, en este caso, el cambio fue debido a otras finalidades, no cubiertas por la alegada; ii) hay poco margen para limitar la libertad de expresión, en general, cuando se trata de materias de interés general; iii) el Tribunal recuerda que los servidores de la justicia deberían autorrestringirse al ejercitar su derecho a la libertad de expresión: «The Court has recognised that

4 Citada en el caso Baka, $\$ 172$.

25 "The Court accepts that changing the rules for electing the president of a country's highest judicial body with a view to reinforcing the independence of the person holding that position can be linked to the legitimate aim of "maintaining the authority and impartiality of the judiciary" within the meaning of Article $10 \$ 2$. [...] The Court considers that this measure could not serve the aim of increasing the independence of the judiciary, since it was simultaneously, and for the reasons set out above (see paragraphs 151-52), a consequence of the previous exercise of the right to freedom of expression by the applicant, who was the highest office holder in the judiciary». 
it can be expected of public officials serving in the judiciary that they should show restraint in exercising their freedom of expression in all cases where the authority and impartiality of the judiciary are likely to be called in question" (énfasis añadido) $^{26}$. De todo lo anterior, no se encuentra justificación a la actuación del Gobierno húngaro y se estima el recurso, porque, además, como afirma el $\$ 175$, incluso asumiendo que las razones alegadas por el Estado demandado sean relevantes, no pueden ser vistas como suficientes para demostrar que la interferencia reclamada fuera «necesaria en una sociedad democrática», a pesar del margen de apreciación permitido a las autoridades nacionales.

i) La última sentencia es la referida al caso Otegi Mondragón y otros c. España, de 6 de noviembre de 2018. Se trata de un caso complejo en el que lo que se discute es si, declarada la parcialidad de uno de los magistrados en un proceso previo ya acabado, ello contamina todos los demás asuntos en que intervienen la mismas personas ${ }^{27}$. Las razones de la admisión del recurso presentado por Otegi y otros son las que siguen: i) la necesidad de distinguir entre los aspectos subjetivo y objetivo de la imparcialidad, de modo que «el comportamiento de un juez puede no sólo suscitar dudas objetivas sobre su imparcialidad para el observador externo (aspecto objetivo), sino que también puede entrañar un cuestionamiento sobre las convicciones personales del magistrado o magistrada (aspecto subjetivo)»; ii) de acuerdo con estos dos criterios, que el Tribunal define, deben examinarse las demandas en las que se reclama la vulneración del art. $6 \mathrm{CEDH}^{28}$; iii) las apariencias de que se está administrando justicia se incluyen en el criterio objetivo: «[...] incluso las apariencias pueden alcanzar una cierta importancia o, en otras palabras, "la

26 Ver, asimismo, los párrafos 162-167 de la sentencia en relación con los requisitos para el ejercicio de la libertad de expresión, donde se citan los casos Kudeshkina, Wille y Olujić.

27 Este asunto proviene de la STC 133/2014, de 26 de julio de 2014, que había declarado que no había causa de recusación en el caso estudiado.

28 «Este Tribunal reitera que la imparcialidad normalmente supone la ausencia de prejuicio o predeterminación y que su existencia o inexistencia se puede analizar desde varias perspectivas. De acuerdo con la doctrina reiterada de este Tribunal, la existencia de imparcialidad a los efectos del artículo 6.1 debe ser analizada de acuerdo con un criterio subjetivo teniendo en cuenta las convicciones personales y el comportamiento de un juez en particular, es decir, analizando si el juez se encontraba afectado por cualquier prejuicio personal o predeterminación en relación a un concreto caso; y también de acuerdo con un criterio objetivo, es decir, analizando si el Tribunal en sí mismo y, entre otros aspectos, su composición ofrecían suficientes garantías para excluir cualquier duda legítima relativa a su imparcialidad» (\$ 52). Ver, asimismo, párrafos 53-57. 
justicia no sólo tiene que aplicarse, sino que también debe ser aparente que se administra"».

Ciertamente, esta sentencia no resulta muy significativa respecto al ejercicio del derecho a la libertad de expresión por el juez, pero es muy interesante para comprender el objeto de la imparcialidad a que se ha venido refiriendo el Tribunal en las sentencias anteriormente examinadas.

\section{CONCLUSIONES DE ESTA PARTE}

1.a El TEDH ha reconocido repetidamente que los jueces son titulares de la libertad de expresión frente al Estado, a pesar de no ser funcionarios. Por ello se aplica el art. $10 \mathrm{CEDH}$.

2. ${ }^{\text {a }}$ Algunas veces la reclamación se funda a la vez en la vulneración del art. 6.1 CEDH, porque reconoce el derecho a que la causa sea vista "por un tribunal independiente e imparcial, establecido por la ley». En los casos en que la falta de imparcialidad ha producido una lesión al mismo tiempo de la libertad de expresión, se utilizan ambos derechos, entendiendo que se ha producido una doble vulneración. Ello obliga al TEDH a pronunciarse sobre ambos, como ocurre, por ejemplo, en los casos Olujić c. Turquía y Baka c. Hungría. No son incompatibles, de modo que puede producirse una vulneración de los dos derechos.

3. ${ }^{\text {a }}$ Normalmente el TEDH examina, en primer lugar, si el derecho reconocido en el art. $10 \mathrm{CEDH}$ ha podido quedar afectado en el caso que se presenta a su consideración. Una vez decide sobre la injerencia que se ha producido, entra a examinar si concurren las causas que pueden justificar la existencia de esta injerencia, de acuerdo con lo establecido en el art. 10.2 CEDH. Para ello el TEDH ha insistido en la necesidad de examinar caso por caso, aunque teniendo en cuenta la jurisprudencia ya existente, lo que lleva muchas veces a resumir las sentencias ya dictadas. Ello ocurre, por ejemplo y entre otros muchos, en el caso Baka c. Hungría.

4. ${ }^{a}$ Cuando se examinan las causas de justificación contenidas en el párrafo 2 del art. $10 \mathrm{CEDH}$ es habitual repetir, como doctrina común, la interpretación que el Tribunal efectuó del derecho a la libertad de expresión en «una sociedad democrática». El párrafo utilizado es el siguiente:

La libertad de expresión constituye uno de los principales fundamentos de la sociedad democrática y una de las condiciones básicas para su progreso y para el libre desarrollo de la personalidad. De acuerdo con el apartado 2 del artículo 10 , es aplicable no solo a la 'información' o a las 'ideas' que son recibidas de 
manera favorable o consideradas inofensivas o se ven con indiferencia, sino también a las que ofenden, conmocionan o molestan. Tales son las demandas del pluralismo, la tolerancia y aceptación sin las que no existe la «sociedad democrática». Tal como dispone el art. 10, esta libertad está sometida a excepciones que deben, sin embargo, interpretarse de forma estricta y cuya necesidad debe ser establecida de forma convincente.

5. ${ }^{a}$ Respecto a la libertad de expresión de los jueces, el TEDH ha considerado que puede ser ejercida frente autoridades superiores, como ocurrió en el caso Wille; autoridades políticas, como en el caso Baka, o judiciales, como en los casos Pitkevich, Kayasu y Kudetshkina.

6. ${ }^{a}$ La libertad de expresión del juez va a quedar restringida cuando las opiniones se manifiestan en medios públicos de comunicación; aunque no esté prohibida la utilización de la prensa, el TEDH aconseja que los jueces sean «discretos» y no utilicen la prensa como vehículo para formular sus opiniones y sus críticas. Ello ocurre en casos como Poyraz, Di Giovanni y Kudeshkina.

7. A Algunos asuntos pueden resultar excluidos de la manifestación pública de la opinión judicial. No cuando se trata del ejercicio combinado de la libertad de expresión y la libertad de cátedra, como ocurre en el caso Wille, donde, aun tratándose de cuestiones relacionadas con modificaciones constitucionales, la actitud posterior del príncipe de Liechtenstein respecto a lo opinado por el juez reclamante en un ciclo de conferencias universitarias produjo la vulneración del derecho a la libertad de expresión de dicho juez. Sin embargo, el Tribunal repite que existe un interés general del Estado cuando se trata de función pública y especialmente lo relativo a la Administración de justicia, que queda incluido en las causas de exoneración en el art. 10.2 CEDH, por la especial naturaleza del Poder Judicial y, al mismo tiempo, por la necesidad de garantizar la independencia y la imparcialidad de los jueces. Un caso significativo es el Di Giovanni, en el que se afirma que se debe vigilar el equilibrio entre la libertad de expresión del juez y el interés legítimo del Estado en garantizar la confianza en los tribunales.

8. ${ }^{a}$ Finalmente se trata el tema de la proporcionalidad entre la declaración del juez y la sanción impuesta. Ello ocurre en el caso Kayasu, en donde se afirma que la sanción a un funcionario de la Administración de justicia, en el caso, un fiscal, tiene un efecto disuasorio sobre el propio funcionario y sobre la profesión en su conjunto, con el consiguiente chilling effect. Pero, además, produce la desconfianza en la Administración de justicia, que debe evitar cualquier Estado.

Como afirmará Climent Gallart (2018: 533-534), si bien los jueces y magistrados gozan de su derecho a la libertad de expresión, «la imparcialidad 
y la apariencia constituyen el principal límite al ejercicio [...]. La autoridad judicial se apoya precisamente sobre la confianza de la ciudadanía y esta solo se puede dar si los magistrados actúan de modo imparcial».

\section{EL EJERCICIO DE LA LIBERTAD DE EXPRESIÓN POR LOS JUECES}

La independencia del juez incluye el ejercicio de su derecho a la libertad de expresión; sin embargo, a partir de aquí se plantean diversos problemas, entre ellos, el de la imparcialidad del juez, porque ¿cómo va a poder decidir imparcialmente un juez que, habiendo ejercido este derecho, debe enfrentarse con un asunto sobre el que ya ha manifestado previa y legalmente su opinión? $\mathrm{Y}$, además, ¿̇tiene restringido el juez el uso de determinados tipos de medios de comunicación, incluidas las redes sociales, para ejercer el derecho?

\section{LIBERTAD DE EXPRESIÓN E IMPARCIALIDAD}

El TJUE ha utilizado un camino complejo para llegar a la conclusión de que en la UE rige la regla del Estado de derecho. Es decir, si los jueces son independientes del poder político de cada país, ello es porque en la UE rige el Estado de derecho, que incluye la independencia del Poder Judicial, y a partir de la sentencia Associação Sindical dos Juizes Portugueses, ha abierto la vía para que puedan presentarse cuestiones prejudiciales relativas a leyes nacionales que se pueda entender que vulneran la independencia judicial. No voy a repetir las nociones de independencia e imparcialidad que he expuesto en la primera parte de este trabajo. Solo voy a recordar que si el derecho a la libertad de expresión corresponde a todos, el art. 10.2 CEDH permite que la ley establezca condiciones, restricciones o sanciones al uso de este derecho, que "son necesarias en una sociedad democrática», cuando se trate de garantizar «la autoridad y la imparcialidad del poder judicial». Pero este es un aspecto que podríamos llamar general y objetivo, porque lo que se plantea no es tanto la cuestión general, sino la subjetiva en cada caso y para cada juez. La pregunta es, por tanto, ¿es totalmente libre un juez de expresar su opinión? ¿Qué efectos va a tener en su actuación como tal juez? Un pequeño repaso a algunas decisiones del TEDH y del TC puede darnos algunas pistas.

a) Algunas sentencias del TEDH han sido ya examinadas, como el caso Pitkevich c. Rusia, el caso Baka c. Turquía o el caso Otegi c. España. Sin embargo, otros casos que se han examinado desde el punto de vista del reconocimiento al juez del ejercicio del derecho a la libertad de expresión 
comportan también problemas de imparcialidad, en cuanto que el reclamante había pedido que se reconociera que se había vulnerado también el art. 6.1 $\mathrm{CEDH}$ en lo relativo a la imparcialidad del juez.

El caso Buscemi c. Italia resulta bastante significativo. Deriva de un procedimiento complicado de custodia de una hija extramatrimonial. En un momento determinado se produce un enfrentamiento entre el reclamante y el presidente del Tribunal de la Infancia de Turín, con cruce de cartas en la prensa, el reclamante consideró que el caso no debía haber sido examinado por un tribunal presidido por un juez que había ya manifestado su opinión en la prensa; el TEDH recuerda la discreción que se exige al juez ${ }^{29}$, discreción que debe disuadirle del uso de la prensa incluso en los casos en que haya existido una provocación. De acuerdo con ello, se estima la violación alegada del art. 6.1 CEDH.

La exigencia de discreción y evitar el uso de la prensa está presente también en las sentencias dictadas sobre el ejercicio de la libertad de expresión por los jueces. Así, la STEDH Kayasu c. Turquía exige gran discreción a las autoridades judiciales $(\$ 100)$, que debe llevarlas a no utilizar la prensa incluso en el caso de provocaciones, debido a la grandeza del rol del juez. La necesidad de la discreción se vuelve a repetir en Olujićc. Croacia (\$59), Poyrazc. Turquía (\$\$ 67-69) y Di Giovanni c. Italia (\$80), por no citar más que aquellos casos en que se discute directamente el ejercicio de la libertad de expresión por el juez. Concretamente, en Poyraz c. Turquía, de 7 de diciembre de 2010, el TEDH declaró que no había habido violación del art. $10 \mathrm{CEDH}$; en este caso se había abierto un expediente a un juez, director de un comité administrativo de la Fundación para la promoción de la justicia a causa de una denuncia anónima de que beneficiaba a un grupo religioso. Este juez había sido

29 «67. The Court stresses, above all, that the judicial authorities are required to exercise maximum discretion with regard to the cases with which they deal in order to preserve their image as impartial judges. That discretion should dissuade them from making use of the press, even when provoked. It is the higher demands of justice and the elevated nature of judicial office which impose that duty [énfasis añadido].

68. The Court considers, as the Commission did, that the fact that the President of the court publicly used expressions which implied that he had already formed an unfavourable view of the applicant's case before presiding over the court that had to decide it clearly appears incompatible with the impartiality required of any court, as laid down in Article $6 \$ 1$ of the Convention. The s statements made by the President of the court were such as to objectively justify the applicant's fears as to his impartiality (see, mutatis mutandis, the Ferrantelli and Santangelo v. Italy judgment of 7 August 1996, Reports 1996-III, p. 952, \$\$ 59 and 60).

69. There has accordingly been a breach of Article $6 ₫ 1$ of the Convention». 
nombrado magistrado del Tribunal de Casación. Cerrado el expediente, se filtró a la prensa. El juez demanda al instructor y este, ante el TEDH, denuncia la violación del art. 6.1 CEDH y del art. 10, relativo a la libertad de expresión. Se produce entonces una colisión entre la libertad de expresión del instructor del expediente y el honor del juez afectado ${ }^{30}$. En la ponderación entre los dos derechos, el filtrador no queda protegido. En definitiva, este es uno de los límites establecidos en el art. 10.2 CEDH.

b) Los derechos fundamentales no son absolutos. No es necesario insistir en esta regla. Pero ¿qué protege la libertad de expresión? Una afirmación general la proporciona Solozábal (1991: 81), cuando dice que protege exclusivamente una sola actividad: la comunicación sin trabas del pensamiento. Díez-Picazo Giménez nos dirá que la esfera de lo constitucionalmente protegido es más la opinión que las noticias (2013: 317). Y todos los autores lo interpretan como un derecho de libertad (Villaverde, 2018: 595).

Hasta este momento, la solución a los problemas planteados parecía clara: quedaba claro cuál era el concepto de incompatibilidad; quedaba más o menos claro el concepto de abstención de los jueces en los asuntos que habían conocido, de acuerdo con las reglas establecidas en el art. 219 LOPJ, y quedaba claro también que un juez puede ejercer su derecho a la libertad de expresión, pero debe asumir las consecuencias que va a comportar respecto a su participación en el asunto sobre el que ha manifestado públicamente su opinión. Aunque también debería distinguirse entre los distintos objetos de la opinión, como ha hecho el TEDH en las distintas sentencias que se han examinado y que, según Climent (2018: in totum), pueden sistematizarse en los siguientes puntos: críticas técnico-jurídicas, colisión con el derecho al

30 «78. Dans l'exercice de leur liberté d'expression, les personnes investies de responsabilités publiques doivent faire montre de retenue pour ne pas créer une situation de déséquilibre lorsqu'elles se prononcent publiquement au sujet de citoyens ordinaires qui, eux, ont un accès plus limité à ces mêmes média. Une vigilance accrue doit être observée par les fonctionnaires publiques dans l'exercice de leur droit à la liberté d'expression dans le contexte d'enquêtes en cours et en particulier lorsque ces fonctionnaires sont eux-mêmes chargés de conduire de tels enquêtes qui contiennent des informations couvertes par une clause officielle de secret dans l'intérêt d'une bonne administration de la Justice".

79. Compte tenu de ce qui précède, les motifs avancés à l'appui de la condamnation du requérant au civil suffisent pour convaincre la Cour que l'ingérence dans l'exercice du droit de l'intéressé à la liberté d'expression était "nécessaire dans une société démocratique" et les moyens employés étaient proportionnés par rapport au but visé, à savoir: "la protection de la réputation ou des droits d'autrui".

80. En conséquence, il n’y a pas eu violation de l'article 10 de la Convention». 
honor de otros jueces, y la utilización de medios de comunicación para responder.

\section{EL EJERCICIO DE LA LIBERTAD DE EXPRESIÓN POR LOS JUECES}

El ejercicio de la libertad de expresión tiene los límites que se establecen para el derecho en el art. 10.2 CEDH. Pero, además, quien ejerce su libertad de expresión tiene que afrontar las consecuencias establecidas incluso cuando se ejerce de forma legal. Por ello debo advertir que los efectos a que me estoy refiriendo no deben ser considerados como una sanción por haber usado la libertad de expresión ${ }^{31}$, sino como un sistema de protección del Estado de derecho que incluye, entre sus elementos estructurales, la independencia del Poder Judicial. Este, en definitiva, garantiza frente a la sociedad la imparcialidad de los jueces y para ello deben tomarse las medidas establecidas en la ley.

Un tipo de medidas son las incluidas en las normas que regulan las causas de abstención y recusación de los miembros del Poder Judicial. En un sistema democrático el ejercicio de la libertad de expresión por el juez tiene dos aspectos: i) el externo, es decir, la protección del Estado de derecho y la relación del juez en la sociedad en la que se inserta para garantizar su independencia, ergo, la recusación, y ii) el interno o subjetivo, consistente en la ponderación por parte del mismo juez de su situación frente al litigio después de o por haber usado su libertad de expresión en lo referente al proceso, es decir, la abstención.

El TEDH ha venido aplicando el que denomina «test objetivo y subjetivo" para determinar la actitud del juez en la utilización de su derecho y la influencia que ello tiene en su imparcialidad. La imparcialidad denota normalmente ausencia de prejuicio, pero puede determinarse mediante la aproximación subjetiva, que consiste en cerciorarse de la convicción personal de un concreto juez en un caso particular, y la aproximación objetiva, que consiste en determinar si el juez ofrece garantías suficientes para excluir cualquier duda legítima al respecto ${ }^{32}$. La más clara aplicación de estos principios se produce en el asunto Otegi c. España (\$ 57), donde se afirma que «incluso las apariencias pueden alcanzar una cierta importancia» o, en otras palabras, «la justicia no sólo tiene que aplicarse, sino que también debe ser aparente que se administra (véase De Cubber, anteriormente citado, $\$ 26$ ). Lo que está en

31 Como parece deducirse de lo ocurrido en el caso Baka c. Hungría y los resueltos por el TJUE citados en la nota 4.

32 Olujić c. Croacia, $\$ \$ 59-60$, citando el caso Buscemi, entre otros. 
juego es la confianza que los tribunales deben inspirar en los ciudadanos en una sociedad democrática. Por lo tanto, cualquier juez respecto del cual pueda existir un motivo legitimo para temer de su falta de imparcialidad debe abstenerse» (énfasis añadido).

\section{LOS JUECES Y LAS REDES SOCIALES}

La aplicación concreta de los principios estudiados hasta aquí se amplía en la actualidad con la problemática referida a la participación de los jueces en otro sistema de comunicación, esta vez más amplio, inmediato y de alcance general, que son las redes sociales. Ya no se trata ahora de discutir si los jueces tienen o no derecho a utilizar su libertad de expresión, ni de si esta utilización puede eliminar su imparcialidad o, al menos, la apariencia de imparcialidad que debe existir. Esto ya está aceptado por la jurisprudencia del TEDH y, en virtud de la aplicación general de dichas sentencias, los países pertenecientes al Convenio Europeo de Derechos Humanos tienen en sus manos la guía de los criterios aplicables para la solución de cada caso concreto. Se trata ahora de examinar si estos nuevos medios de comunicación social inciden o no en las líneas antes resumidas. En definitiva, si deben equipararse a la prensa, la radio y los medios tradicionales a los que ha tenido ocasión de referirse el TEDH, o requieren un nuevo y distinto set de criterios. Puede resultar interesante el resumen de los medios al alcance que en abril de 2010 efectuó el Comité de Códigos de Conducta de la Conferencia Judicial de Estados Unidos. Sé que hay más social media desde entonces, pero creo que, teniendo características diferentes, pueden asimilarse a los que describen ahí. Según este documento ${ }^{33}$, las redes sociales se refieren a la construcción online de comunidades de gente que comparte intereses o actividades; permiten crear y editar perfiles profesionales o personales que contienen información que puede ser vista por otros en las redes sociales que otros pueden crear o unirse a ellas. Según el documento al que me refiero, debe distinguirse entre las redes sociales que ofrecen conexiones personales y redes profesionales, de cualquier tipo.

Las tipologías de las distintas redes actualmente en funcionamiento son las siguientes: i) Facebook: proporciona una vía fácil para la gente para mantenerse en contacto y estar en la red, sin necesidad de crear una web; ii) LinkedIn: se usa más en el mundo de los negocios y ofrece sistemas de promoción; iii)

33 Committee on Codes of Conduct. Judicial Conference of the United States. Resources Packet for Developing Guidelines on Use of Social Media by Judicial Employees. Abril de 2010. 
blog: es un tipo de web que proporciona comentarios, noticias, diarios online, y a veces permite entrar para añadir comentarios, compartir imágenes y combinar con otros blogs; iv) Twitter: combina mensajería instantánea y blogging, está basado en textos de 140 caracteres, que se muestran en la página del autor a sus suscriptores, que reciben el nombre de seguidores o amigos; se puede abrir o cerrar el acceso a un círculo de amigos, o establecer un acceso abierto, y v) YouTube: es un sistema para compartir vídeos ${ }^{34}$.

La tipificación de los sistemas de distintas formas de comunicación en las redes sociales lleva a una pregunta: ¡existe diferencia entre los medios tradicionales de comunicación social y los nuevos medios electrónicos? Mi percepción es negativa, en el sentido de que todos tienen un elemento común, la comunicación de noticias u opiniones a un sector de población que está fuera del núcleo donde se genera la noticia. Por tanto, en una primera aproximación, debería considerarse que las reglas que pueden deducirse de las sentencias del TEDH que se han examinado en páginas precedentes deberían ser aplicadas también cuando se trata de redes sociales. En diferentes grupos profesionales internacionales que trabajan en los temas de independencia, imparcialidad e integridad de los jueces, se han planteado una serie de cuestiones que se refieren al uso de las redes sociales por parte de los jueces y las consecuencias que pueden comportar en la protección de los principios que deben presidir su actuación, porque no hay que olvidar que "[l]a independencia judicial es un derecho de todo ciudadano o ciudadana cuya protección y defensa forma parte inexcusable de los deberes profesionales del juez y la jueza, y no un privilegio personal de su estatuto ${ }^{35}$ (énfasis añadido).

Creo que la regla general sigue siendo la misma que he venido defendiendo hasta aquí: los jueces pueden utilizar las redes sociales. Como afirma la

34 El asunto de la participación de los jueces en las redes sociales tiene también repercusión en la prensa especializada. Por ejemplo, el 24 de mayo de 2019, Clin Perkel publicó en La presse canadienne una noticia titulada «La présence des juges sur les réseaux sociaux examinée», donde se preguntaba si es justo y al mismo tiempo deseable exigir al Poder Judicial que se mantenga aislado y alejado de todos los compromisos sociales activos (https://bit.ly/2UykENN). Unos meses más tarde, el 30 de octubre del mismo año, Marine Babonneaule publica en Dalloz Actuallité un trabajo titulado "Réseaux sociaux et pouvoir judiciaire: la néccessaire incarnation?», en el que se hace eco del caso de un juez español que había declarado en Twitter sus opiniones sobre las razones de las violencias conyugales, y resume un coloquio sobre las influencia de las redes sociales en la conducta de los jueces organizado por la Escuela Nacional de la Magistratura francesa y dirigido por la magistrada Clémence Caron (https://bit.ly/3gY1NTF).

35 Consejo General del Poder Judicial. Código ético para la Carrera Judicial. Principio 1. 
Declaración de Doha ${ }^{36}$ : «Es importante que los jueces, tanto como ciudadanos, como en el ejercicio de sus funciones jurisdiccionales, se involucren en las comunidades en las que sirve», y, en consecuencia, «el beneficio público de dicho involucramiento debe estar en equilibrio con la necesidad de mantener la confianza de la población en el Poder Judicial, el derecho a un juicio justo, así como la imparcialidad, integridad e independencia del sistema judicial en su conjunto».

Podemos distinguir diversas situaciones:

1. ${ }^{\circ}$ Las redes sociales institucionales. Son aquellas a través de las que los tribunales dan a conocer sus decisiones, la estructura de los tribunales, el funcionamiento de la Administración de justicia, etc. Un ejemplo de ello lo encontramos en la web www.poderjudicial.es. Estas no presentan ningún problema por lo general y contribuyen a hacer más accesible la justicia, la transparencia y la confianza pública en la comprensión del funcionamiento de los tribunales ${ }^{37}$.

2. ${ }^{\circ}$ Las redes sociales que configuran grupos de personas para discutir acerca de problemas relacionados con su profesión. Por ejemplo, cuando se crea un blog exclusivamente dirigido a la discusión de sentencias relacionadas con un aspecto concreto. Estos blogs tampoco deberían ofrecer mayores problemas, siempre y cuando se limiten al intercambio de opiniones y no pretendan imponer opiniones jurídicas sobre el caso que tiene entre manos un concreto juez.

3..$^{\circ} \mathrm{El}$ aspecto más importante es el relacionado con la utilización personal de las redes sociales. Es aquí donde se presentan los problemas más discutidos.

\section{INDEPENDENCIA EN LAS REDES SOCIALES}

Ninguno de los documentos de soft law que se pronuncian sobre la participación de los jueces en las redes sociales y que se titulan a sí mismos como

36 UNODOC. «Non-binding Guidelines on the use of social media by judges». Declaración de Doha: promover una cultura de legalidad. Global Judicial Integrity Network.

37 Aparecen en el punto 11 del documento citado en la nota anterior, que dice textualmente: «El uso institucional (en contraste con el individual) de las redes sociales por parte de los tribunales puede, en circunstancias apropiadas, ser una herramienta válida para promover: (a) el acceso a la justicia; (b) la administración de justicia y en particular, la eficiencia judicial y la tramitación de casos con prontitud; (c) rendición de cuentas; (d) transparencia, y (e) confianza pública en la comprensión y respeto de los tribunales y el Poder Judicial». 
«normas éticas» hacen otra cosa más que aconsejar prudencia y no sanciones. A título de ejemplo, el Código Ético para la Carrera Judicial, aprobado por el CGPJ, en su preámbulo dice expresamente que «nada tiene que ver el régimen disciplinario con la ética judicial», ya que esta "solo es concebible en términos de estricta voluntariedad y ausencia de responsabilidad legal», y añade que "opera como estímulo positivo en cuanto dirigida a la excelencia», que se traduce en «la promesa de una justicia buena en cuanto incorpora las cualidades necesarias para lograr el fin que se le asigna en la Constitución: la tutela de los derechos de la ciudadanía». Por ello, en el punto 9, se dirá que «el juez y la jueza han de comportarse y ejercer sus derechos en toda actividad en la que sean reconocibles como tales de forma que no comprometan o perjudiquen la percepción que, en un Estado democrático y de Derecho, tiene la sociedad sobre la independencia del poder judicial». Como ya he dicho, este documento no se refiere para nada a la problemática de las redes sociales; sin embargo, el dictamen de la Comisión de Ética Judicial ${ }^{38}$, de 25 de febrero de 2019 (consulta 10/2018), responde a las preguntas formuladas sobre la utilización por los jueces de cualquiera de las redes sociales. Llega a las siguientes conclusiones: i) no hay inconveniente en que un juez utilice un pseudónimo, aunque ello no permite saltarse las normas que rigen su actuación; ii) distingue entre los grupos cerrados, a los que me he referido antes, y el acceso libre; en este último caso la valoración ética es más compleja; iii) cuando se trate de opinar sobre cuestiones jurídicas debe tenerse en cuenta que pueden «comprometer no solo la apariencia de imparcialidad", sino que en determinadas circunstancias también pueden afectar a la propia imparcialidad, a la independencia y a la integridad del juez; iv) el uso de las palabras "amigo" o «seguidor» en una red social no compromete la independencia e imparcialidad del juez. A las mismas conclusiones llega el ya citado dictamen de la misma comisión de 14 de enero de 2021.

Las conclusiones de este dictamen coinciden con lo expuesto hasta aquí. Es decir, en uso de su libertad de expresión, los jueces pueden expresar sus opiniones jurídicas o no, pero ello puede alterar la apariencia de independencia e imparcialidad, por lo que, y en consonancia con lo que las decisiones del TEDH han venido señalando, existe un deber ético de prudencia y mesura $^{39}$.

38 CGPJ. Dictamen de la Comisión de Ética Judicial de 25 de febrero de 2019 (consulta 10/2018).

39 Un estudio interesante de derecho comparado es el de Ordónez Solís «iiiPero bueno, los Jueces también están en las redes sociales!!!”, en el Diario LA LEY, n. ${ }^{\circ} 8762$, de 16 de mayo de 2016. 
El régimen descrito debe tener sus excepciones, que no dejan de ser las que ya hemos visto en el anterior apartado respecto, por ejemplo, a situaciones políticas extremas, incumplimiento por los poderes públicos de los derechos fundamentales o de las normas del Estado de derecho y otros semejantes. Si los jueces están autorizados en uso de su libertad de expresión a hacer estas denuncias, importa poco el medio que utilicen para realizarlas. Las soluciones a los casos examinados por el TJUE y por el TEDH son absolutamente aplicables.

Ahora bien, siendo ello así, ¿cuáles van a ser las consecuencias de un uso «imprudente» de la libertad de expresión en las redes sociales? Existe una primera respuesta: a no ser que se incurra en alguno de los supuestos en que de acuerdo con las normas reguladoras de la disciplina judicial esté prevista una sanción, la respuesta viene dirigida a la protección de la independencia e imparcialidad judicial, que forman parte del Estado de derecho. Es decir, el sistema constitucional incluye como elementos esenciales la independencia e imparcialidad judiciales, y, por ello, el legítimo ejercicio de la libertad de expresión debe tener sus consecuencias. Por ello, pienso que pueden distinguirse dos aspectos: el externo y el propio de cada juez. Para ello funcionan los mecanismos de la recusación y de la abstención. El juez que ha opinado legítimamente sobre asuntos jurídicos sobre los que puede tener un interés, ya sea en un momento anterior, ya sea con posterioridad a haber formulado la opinión correspondiente, puede ser recusado. Es decir, puede considerarse que el juez es sospechoso de parcialidad o que tiene un prejuicio o predisposición a una determinada solución, como puede leerse en los Principios de Bangalore ${ }^{40}$. Esta situación puede darse tanto por medio de expresiones físicas como opiniones jurídicas previas, o la pertenencia de un juez a un partido político concreto $^{41}$. Y lo mismo ocurre respecto a relaciones familiares o de amistad.

40 Valor 2: Imparcialidad. 2.1, n. ${ }^{\circ}$ 57: «Se ha definido la predisposición o prejuicio como una simpatía, inclinación, preferencia o favoritismo hacia una u otra parte o hacia un resultado determinado. En su aplicación a los procesos judiciales, representa una inclinación a decidir una cuestión o fallar una causa de cierta manera que no deja la mente judicial plenamente abierta al convencimiento [...]».

41 Principios de Bangalore. Valor 2: Imparcialidad. 2.2, n. ${ }^{\circ}$ 65: «Fuera del tribunal, un juez debe evitar el empleo deliberado de palabras o una conducta que pueda razonablemente crear una percepción de falta de imparcialidad. [...] La actividad política partidista o las afirmaciones del juez emitidas fuera de los tribunales con respecto a una controversia pública de carácter partidista pueden minar su imparcialidad y generar confusión pública acerca de la naturaleza de la relación entre la judicatura y los poderes ejecutivo y legislativo del Estado [...]». Un caso interesante de aplicación 
Estas mismas causas pueden llevar o deberían llevar al juez a abstenerse. Por ello es lógico que en el sistema judicial español las mismas causas funcionan como de recusación, porque se están reconociendo así los aspectos externos, que permiten a un tercero posiblemente afectado que excluya del proceso al juez que ha manifestado su opinión o que tiene relaciones de parentesco o amistad con quien está relacionado con el proceso. $\mathrm{Y}$ al mismo tiempo funcionan a nivel interno del propio juez, que sabe que por estas razones debe abstenerse de participar en el concreto proceso. De este modo, las causas de abstención y recusación funcionan como garantías de la efectiva imparcialidad e independencia del juez.

\section{CONCLUSIONES}

Todo lo dicho hasta aquí lleva a una única conclusión: los principios de independencia e imparcialidad de los jueces constituyen un elemento indispensable del Estado de derecho. La titularidad de los jueces de su derecho a la libertad de expresión no puede ser eliminada por su condición de tales. Es indiferente el medio que utilicen para ejercer este derecho, pero han de atenerse a las consecuencias que conlleva su ejercicio, porque puede destruir la presunción de imparcialidad y entonces entrarán en el círculo de las causas de recusación y de abstención, porque solo así se cumplen los principios del Estado de derecho.

\section{BIBLIOGRAFÍA}

Bastida Freijedo, F. J. (2018). Artículo 20.1, 2 y 4. En P. Pérez Tremps y A. Saiz Arnaiz (dirs.). Comentario a la Constitución española: 40 aniversario 1978-2018: libro-homenaje a Luis López Guerra (pp. 465-474). Valencia: Tirant-Lo Blanch.

Climent Gallart, J. A. (2018). La jurisprudencia del TEDH sobre la libertad de expresión de los jueces. Revista Boliviana de Derecho, 25, 526-534.

Díez-Picazo Giménez, L. (2013). Sistema de Derechos Fundamentales. Cizur Menor: Civitas-Thomson Reuters.

de la doctrina sobre imparcialidad del Tribunal Constitucional es el referido a la recusación del presidente Fco. Pérez de los Cobos por su pertenencia a un partido político, del que se dio de baja poco después. Véanse AATC 180/2013, de 17 de septiembre; 237/2013, de 21 de octubre, y 238/2013, de 21 de octubre, que rechazaron que concurriera ninguna causa de recusación de las previstas en el art. 219. 
Requejo Pagés, J. L. (1989). Jurisdicción e independencia judicial. Madrid: Centro de Estudios Constitucionales.

Solozábal Echavarría, J. J. (1991). La libertad de expresión desde la teoría de los derechos fundamentales. Revista Española de Derecho Constitucional, 32, 73-114.

Villaverde Menéndez, I. (2018). Comentario al art. 20 CE. La libertad de expresión. En M. Rodríguez Piñero y M. ${ }^{a}$ E. Casas Baamonde (dirs.). Comentarios a la Constitución española (pp. 581-616). Madrid: Boletín Oficial del Estado. 